\title{
The Emergence of Teacher Leadership in TESOL: An Exploratory Study of English Language Teachers as Teacher Leaders in the Saudi EFL Context
}

Sayyed Rashid Ali Shah*

\begin{abstract}
As part of a larger qualitative case study, this article explores the notion of teacher leadership in English as a Foreign Language (EFL) context and a higher educational institution in Saudi Arabia. Twelve EFL teacher leaders were interviewed to understand their perceptions of teacher leadership practices in the EFL context. Qualitative data were collected through semi-structured interviews and opened-ended questionnaires, and analysed using NVivo10. Data analysis led to 18 main categories and four overarching themes; however, four major categories and one key theme are part of this article that represent the EFL teacherleaders' perceptions of their leadership practices and roles at the English Language Institute (ELI). The findings reveal that teacher leadership is a novel concept at the ELI and teacher leaders operate in hierarchical leadership structures. However, their wide range of leadership roles, both instructional and operational match with the three historical waves of teacher leadership (Silva, Gimbert \& Nolan, 2000) in the US context. The impact of hierarchical structures on teacher leadership practices is evidently found as EFL teacher leaders encounter various difficulties, such as heavy administrative workload and lack of autonomy. Nevertheless, their shared leadership practices within the groups help them deal with these challenges.
\end{abstract}

Key Words: Educational leadership, EFL teacher leaders, EFL context, hierarchical leadership structures, shared leadership practices, teacher leadership, TESOL professionals.

\section{Introduction}

The increasing professional demands of educational institutions have led to the rise of the phenomenon of teacher leadership, a "process by which teachers, individually or collectively, influence their colleagues, principals, and other members of school communities to improve teaching and learning practices with the aim of increased student learning and achievement" (Katzenmeyer \& Moller, 2009, p. 288). Although largely in western contexts, the process of teacher leadership empowers teachers to affect change in their schools and perform a variety of leadership roles. Going beyond their pedagogical responsibilities, teacher leaders think not only of the achievement of their learners, but of the success of their schools as well.

Teacher leadership roles, such as curriculum coordinator, subject specialist, mentor and teacher trainers, are considered crucial to school development due to the teacher leaders' ability to undertake major tasks, influence changes and reforms, and serve as a bridge between the top leadership and fellow teachers. Their pivotal role in school functioning has convinced educational organisations around the world to assign teachers leadership responsibilities and empower them to contribute to the effectiveness of their organisations.

\footnotetext{
* Assist. Prof. Dr. Faculty of Languages \& Translation, King Khalid University, Abha, Saudi Arabia Corresponding email: sashah@kku.edu.sa
} 
Although the significance of teacher leadership roles is widely acknowledged in mainstream education, its presence in the field of Teaching English to the Speakers of Other Languages (TESOL) is scarce. Liu (2008) suggests that, to meet global challenges in the ELT world and achieve professional excellence, every TESOL professional should take a range of active roles and contribute to the success of their organisation and the TESOL profession. However, there is a serious lack of empirical research on how teacher leadership appears and what different roles English language teachers perform as teacher leaders in the field of TESOL. Therefore, this study offers an opportunity for ELT professional as EFL teacher leaders to share their perceptions of the concept of teacher leadership and the nature of leadership practices in an EFL context.

\section{Theoretical framework}

Teacher leadership was first introduced by John Dewey to suggest teachers' active participation in school governance. More recently, teacher leadership practices can be seen in 1980s-educational reform movement in the US which has continued to develop in three evolutionary waves (Silva et al., 2000).

In early 1980s, the first wave considered teachers, such as department chairs, master teachers and union representatives, with more formal roles and top-down authority. These roles implied power structures that affected teachers' and leaders' relationship. Moreover, rigid bureaucratic structures led to managerialism and constricted supervision of teachers and teacher leaders in a bid to "further the efficiency of school operations" (York-Barr \& Duke, 2004, p. 260). TESOL professionals during this time suffered from low job status in public education and many ESL teachers found it difficult to secure leadership positions (Sams, 2010).

The second wave of teacher leadership emerged to address the shortcomings of the first one, which "acknowledged the importance of teachers as instructional leaders" (Silva et al., 2000, p. 780). The pedagogical knowledge and skills of teachers opened vistas for them to take instructional leadership roles, such as team leaders, curriculum developers, PD specialists and mentors. Although teachers' expertise was acknowledged in this wave, their positions were still considered the continuation of hierarchical roles (Silva et al., 2000).

The third wave that appeared in the 1990s is considered the emerging form of teacher leadership and is still evolving in educational organisations around the world. In contrast with the other two waves, this wave is focused on teachers' daily work as part of their leadership roles and aims to improve the teaching profession and contributes to institutional reforms through collaborative efforts.

\subsection{Definition of teacher leadership}

Teacher leadership refers to "taking the initiative to improve practice, acting strategically with colleagues to embed change, gathering and using evidence in collaborative processes, contributing to the creation and dissemination of professional knowledge" (Frost, 2010, p. 210). For improved teaching and learning, teacher-leaders often require to possess expertise in areas, such as curriculum development, professional development and evaluation. Swanson, Elliott and Harmon (2011, p. 153) argue that teacher leadership is the blend of "knowledge, skills and dispositions demonstrated by teachers" to enhance the effectiveness of schools. Likewise, Bangs and MacBeath (2012) emphasise the core capabilities of teacher leaders and concisely define the concept of teacher leadership: 
Most typically it refers to teachers' individual agency, often with reference to classroom management and pedagogy but in some cases referring to wider collegial influence with colleagues, with curriculum development and policy-making within or across schools. As well as being cast as an individual activity, teacher leadership may also refer to groups or teams of teachers with a leadership remit for aspects of policy and practice (p. 331).

The definition by Bangs and MacBeath (2012) bears the features of transformational leaders who "enable their colleagues to do things that they wouldn't ordinarily do on their own to improve their professional practice" (Wasley, 1991, p. 4). This echoes with Murphy's (2007) interpretations that teacher leadership has an enabling factor that is seen in collegial influence from teacherleaders for enhanced professional practices. York-Barr and Duke (2004) further expound the notion by considering it: "the process by which teachers, individually or collectively, influence their colleagues, principals, and other members of school communities to improve teaching and learning practices with the aim of increased student learning and achievement" (p. 287-288).

Katzenmeyer and Moller (2001, p. 2) consider teacher leadership as "a sleeping giant" and believe that teacher leaders' lead within and beyond the classroom, identify with and contribute to a community of teacher learners and leaders, and influence others towards improved educational practice (Katzenmeyer \& Moller, 2001, p. 17)

The definitions by Katzenmeyer and Moller (2001) and York-Barr and Duke (2004) suit the context of this study, as teacherleaders at the ELI lead within and beyond the classrooms and are not completely removed from classroom teaching. Furthermore, their leadership roles are assigned based on their pedagogical and professional expertise which enable them to influence colleagues and work together towards a common goal to achieve institutional outcomes.

\subsection{Teacher leader roles}

Literature on teacher-leader roles is mainly from the US school context (e.g. Katzenmeyer \& Moller, 2001; York-Barr \& Duke, 2004) in which teachers perform a wide array of managerial and instructional leadership roles (Muijs et al., 2013). In line with the first and second waves of teacher leadership, these roles encompass department chairs, mentors, coaches, curriculum reformers, instructional leaders and subject coordinators in which teacher leaders aim to implement institutional policies (Margolis \& Doring, 2012; Thompson \& Wolstencroft, 2015). In a similar vein, York-Barr and Duke (2004) in their meta-analysis of the literature on teacher leadership have identified four roles which are aligned with the first and second wave: teacher leaders as middle managers, curriculum experts, staff developers, and mentors of novice teachers. In more informal leadership roles, such as peer coaching, leading a new team, setting up action research groups and assisting in the development of school curricula (Katzenmeyer $\&$ Moller, 2001), teacher-leaders work collaboratively to contribute to organisational improvement and professional learning of their colleagues. As there is lack of research on English language teachers' perceptions of their leadership roles, this study will fill that gap in TESOL.

\subsection{Hierarchical structure as a barrier to teacher leadership}

As teacher leadership promotes a culture of collaboration, it may be an uphill task in more traditional and top-down management systems. Literature illustrates that organisational structures and professional barriers can hinder teacher leadership in a school context, as bureaucratic, top-down and hierarchical school cultures are obstacles to collaboration, learning and development (Murphy, 2007; Sanocki, 2013). Likewise, Silva et al. (2000) note that "organisational characteristics and structural components can adversely impact the work of teacher leaders" (p. 790). For example, in technocratic systems, 'professional barriers' in the form of administrative workload, lack of autonomy and professional support and added responsibilities often result in teacher-leaders' burnout that obstruct teacher leadership and make teachers feel isolated and less connected to their peers (Harris \& Muijs, 2004). 
This isolation is mainly the upshot of teachers' resentment and their lack of trust in teacher leadership roles as teacher leaders are perceived as an extension of top management.

Bureaucratic structures often lead to control and accountability that make it difficult to reach a common goal and to optimise the balance of formalisation, centralisation and standardisation in educational institutions (Tschannen-Moran, 2009). Consequently, organisations compromise efforts to create a collaborative professional work environment.

Bureaucratic structures - such as hierarchy of authority, division of labor with specialization, and written rules and policies - assist schools to deal with the magnitude and complexity of their resources and tasks. However, overreliance on these structures by leaders will interfere with organizational dexterity and be counterproductive to the goals that schools strive to achieve. As such, professional structures-such as opportunities for collective inquiry, scrutiny, reflection, and decision-making — will need to be more fully integrated into school bureaucracies to promote teacher professionalism and school success (p. 218).

In the field of ELT, Shah (2014) indicates that hierarchical leadership structures impact pedagogical practices in the Saudi context. In an exploratory study, he found that top-down management model led to the lack of collaboration and interpersonal trust and EFL teachers' lack of empowerment. Since no previous research has considered the impact of hierarchical leadership structures on EFL teacher leadership prices, this study will bridge that gap in ELT.

\subsection{Teacher leadership in TESOL}

According to Dove and Honigsfeld (2010), "it is only natural that the development of teacher leaders, in formal as well as informal positions, would be an important means to provide instructional support to teachers in order to enhance learning for ELLs" (p. 5). Leadership among ESL teachers can help design and shape an inclusive curriculum and service delivery for ELLs and provide a means for continual in-class teacher support through the facilitation of coteaching and collaboration strategies (CaustonTheoharis \& Theoharis, 2008). Frequently, ESL teachers are the individuals who may make the first move toward developing a coteaching partnership or other collaborative team efforts to support ELLs in learning grade-level curriculum.

Dove and Honigsfeld (2010, p. 14) offer a table on ESL teacher leadership roles and responsibilities.

\begin{tabular}{|c|c|}
\hline Established Teacher Leadership Responsibilities & Co-teacher Leadership Responsibilities \\
\hline Mentor new teachers & $\begin{array}{c}\text { Identify leadership roles and individual } \\
\text { responsibilities of each teacher }\end{array}$ \\
\hline $\begin{array}{c}\text { Provide input for evaluating teacher responsibilities } \\
\text { of each teacher performance }\end{array}$ & $\begin{array}{c}\text { Propose, implement, and evaluate the effectiveness } \\
\text { of co-teaching models }\end{array}$ \\
\hline Serve on district policy boards and committees & Establish regular avenues of communication \\
\hline Present in-house professional development & Outline and agree on decision-making approaches \\
\hline Promote and support grant-writing opportunities & Provide strategies to meet ELL needs \\
\hline Act as in-class literacy coach & Model and observe in-class lessons \\
\hline
\end{tabular}




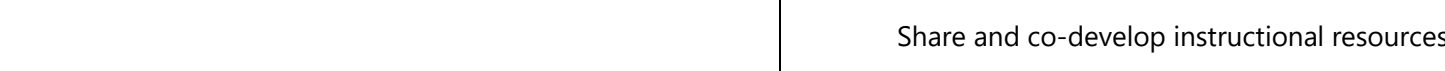

Their recommendations for current and future ESL and mainstream collaborative teacher leaders are as follows:

- $\quad$ Start small.

- Have realistic expectations for yourself and your colleagues

- Look for "found time" for planning, or explore electronic means of communication.

- Over time, expand joint planning and parallel teaching to more extensive collaborative initiatives.

- Advocate for establishing collaborative teacher practice as an accepted form of professional development (Dove \& Honigsfeld, (2010, p. 18-19).

As most of the studies on teacher leadership have been carried out in the US and the UK contexts, there is a serious dearth of empirical research on this issue in the field of TESOL. The TESOL industry is growing day by day and managing language institutions and programmes have become essentially challenging for TESOL professionals. Hence, to meet the challenge of $21^{\text {st }}$ century education, the emergence of teacher leadership in TESOL has become indispensable. To explore the construct of teacher leadership in TESOL domain, this study aims to contribute to the body of knowledge by answering the following research questions:

1. How do EFL teacher-leaders perceive the concept of 'teacher leadership' and their leadership roles in the Saudi EFL context?

2. How does 'teacher leadership' appear in the Saudi EFL setting and which role-related challenges are associated with teacher leadership roles at the ELI?

\section{Context of the study}

Saudi culture is largely the combination of Islamic (religious) and tribal values or social traditions, which influence people's beliefs and dispositions at their personal, social and professional levels. The strict social codes of the tribes, together with historically influenced patriarchal family structures, are the key features of Saudi society. These codes influence social interaction which manifests a strong gender segregation sanctioned by the government and society. To ensure gender segregation, there are separate schools, universities and banks for women across the kingdom (Ezzi et al., 2014).

In Saudi Arabia, the influence of tribal culture can be seen in the functioning of educational organisations that are vested in hierarchical management models. The educational institutions aim to support and sustain gender divisions and power relations through gender-segregated educational institutions and differentiated curriculums for male and female students (El-Sanabary, 1994). Reflecting the patriarchal social structures, higher education institutions are controlled by the Saudi government through a hierarchical power structure. The top authority is the Council of Saudi Higher Education, which is responsible for regulating and supervising the HE system. The council, being chaired by the Saudi king, consists of the presidents of state owned universities, members of the Ministry of Education, Higher Education, Labour, Economy and Planning, Social Affairs, Civil Services and Finance. The council directs HE policies at the national level, introduces rules and regulations, and approves the formation of new universities and programmes (Al-Eisa \& Smith, 2013). The MHE ensures the successful implementation of these rules, policies and decisions, and supervises the progress of all the universities. These state-owned universities abide by the regulations of the 
council, which offers a framework for internal governance (General Secretariat, 2007). The hierarchical structure helps the council to control and administer the day-to-day business of the universities across the kingdom. In line with the patriarchal social structures of Saudi Arabia, all the universities' presidents and vice presidents are males, who oversee the affairs of both the men's and women's campuses.

\subsection{The context of the English Language Institute (ELI)}

This exploratory case study was carried out in the English Language Institute (ELI) of a state-owned Saudi Arabian university. In the Men's campus of the ELI, more than 8000 EFL learners enroll to the Preparatory Year Programme (PYP) each year. The language learning needs of these learners are met by more than $250 \mathrm{EFL}$ instructors from 27 different countries who offer 18 hours of language instruction per week.

ELI has a traditional top-down management model which is led by the Dean and six Vice-Deans, who oversee the administrative and academic operations in the institute. The leadership positions in table 1 are in the middle of the institutional hierarchy. Individuals in these roles are principally EFL teachers who connect top leadership with teachers at the ELI. These roles fall precisely into the teacher leadership categories identified by York-Barr and Duke (2004), which are: academic coordination, curriculum development, professional development, quality assurance, tests and examination preparation, and teacher evaluation.

Table 1: Units run by EFL teacher leaders at the ELI

\begin{tabular}{ll}
\hline Administrative Units & Academic Units \\
\hline Academic \& Educational Development System Unit & Graduate Studies Unit \\
\hline Student Affairs Unit & Student Support Unit \\
\hline Academic Coordination Unit & Research Unit \\
\hline Quality Application Unit & Testing Unit \\
\hline External Student Affairs Unit & E-learning Unit \\
\hline Faculty Affairs Unit & Professional Development Unit \\
\hline Cooperative and Practical Training Unit & Curriculum Unit \\
\hline
\end{tabular}

The potential teacher-leaders were selected based on their leadership qualities, management experience, interpersonal skills, organizational skills, professional involvement, enthusiasm, knowledge of cultural sensitivity, flexibility, and background of TESOL (Faculty Handbook). Faculty members and EFL students interact with the institute through 21 units that assist with issues pertaining to curriculum, professional development, schedules, examinations and attendance. 14 out of 21 units are led by nonSaudi nationals who are primarily English language teachers and have been assigned administrative and academic roles based on their expertise. Despite leadership responsibilities, teacher leaders at the ELI are not completely removed from classroom teaching as they teach a minimum of three hours per week as per the university policy. Based on the ELI appraisal scheme, these individuals possess excellent classroom teaching skills and enjoy the status of high rank language teachers. 


\section{Methodology}

This study adopts a qualitative case study methodology to gain insights into how EFL teacher- leaders perceive teacher leadership at the ELI. This methodology suits the nature of the current research, as case study is "an empirical enquiry that investigates a contemporary phenomenon within its real-life context ...where multiple sources of evidence are used" (Yin, 1994, p. 13). Similarly, Cohen et al. (2011) refer to the nature of a case study:

A case study provides a unique example of real people in real situations, enabling readers to understand ideas more clearly than simply by presenting them with abstract theories or principles. ...contexts are unique and dynamic; hence case studies investigate and report the real life, complex dynamic and unfolding interactions of events, human relationships and other factors in a unique instance (Cohen et al., 2011, p. 289).

\subsection{Participants}

Purposive sampling fitted the nature of this study and allowed me to seek in-depth information from experienced EFL teacher leaders who were in a strong position to give it (Cohen et al., 2011). As shown in table 2, twelve male EFL teachers who were promoted to the teacher leadership roles based on their professional and pedagogical expertise, participated in the study. Their varied professional and learning experiences gave more depth and richness to the data, which offer useful insights into the nature of EFL teacher leadership at the ELI. With their permission, all 12 interviews were recorded on a Sony digital recorder and saved on a password-protected laptop with audio tracks labelled under their pseudonyms. The pseudonyms used in this study were chosen by the participants. Eight participants responded to open-ended questionnaire which were saved under their pseudonyms' files. Due to social and cultural constraints, female EFL teacher leaders could not be approached and thus were not included in this study.

Table 2: Research participants

\begin{tabular}{|l|l|l|l|l|l|l|l|}
\hline \multirow{2}{*}{ Pseudonym } & Nationality & $\begin{array}{l}\text { Leadership } \\
\text { Role }\end{array}$ & $\begin{array}{l}\text { Academic } \\
\text { Qualification }\end{array}$ & $\begin{array}{l}\text { Previous } \\
\text { Profession }\end{array}$ & $\begin{array}{l}\text { TESOL } \\
\text { Background }\end{array}$ & $\begin{array}{l}\text { Years of } \\
\text { Leadership } \\
\text { experience } \\
\text { outside ELI }\end{array}$ & $\begin{array}{l}\text { Years of } \\
\text { EFL } \\
\text { Leadership } \\
\text { Role at ELI }\end{array}$ \\
\hline Gray & British & $\begin{array}{l}\text { Head of } \\
\text { Graduate } \\
\text { Studies Unit }\end{array}$ & $\begin{array}{l}\text { PhD in Applied } \\
\text { Linguistics/MA } \\
\text { Education/CELTA }\end{array}$ & $\begin{array}{l}\text { Electrical } \\
\text { Engineering }\end{array}$ & Yes & 4 & 2 \\
\hline Australian & $\begin{array}{l}\text { Head of } \\
\text { Academic \& } \\
\text { Educational } \\
\text { Development } \\
\text { System Unit }\end{array}$ & $\begin{array}{l}\text { B.SC } \\
\text { Engineering/CELTA }\end{array}$ & Engineer & No & 8 & 5 \\
\hline
\end{tabular}




\begin{tabular}{|c|c|c|c|c|c|c|c|}
\hline Harrison & British & $\begin{array}{l}\text { Head of } \\
\text { Research } \\
\text { Unit }\end{array}$ & $\begin{array}{l}\text { MA in Educational } \\
\text { Management \& } \\
\text { Leadership }\end{array}$ & $\begin{array}{l}\text { Secondary } \\
\text { School } \\
\text { Teacher }\end{array}$ & No & 2 & 3 \\
\hline Ibrahim & $\begin{array}{l}\text { Pakistani } \\
\text { Canadian }\end{array}$ & $\begin{array}{l}\text { Head of E- } \\
\text { learning Unit }\end{array}$ & $\begin{array}{l}\text { PhD in } \\
\text { Educational } \\
\text { Leadership }\end{array}$ & Bureaucrat & No & 20 & 3 \\
\hline Ismael & Algerian & $\begin{array}{l}\text { Head of } \\
\text { Student } \\
\text { Support Unit }\end{array}$ & $\begin{array}{l}\text { MA in Educational } \\
\text { Leadership }\end{array}$ & State Agent & No & 4 & 7 \\
\hline Khan & Pakistani & $\begin{array}{l}\text { Head of } \\
\text { Testing Unit }\end{array}$ & $\begin{array}{l}\text { MA in Educational } \\
\text { Leadership }\end{array}$ & $\begin{array}{l}\text { College } \\
\text { Level } \\
\text { Teaching }\end{array}$ & No & 0 & 7 \\
\hline Moh & British & $\begin{array}{l}\text { Head of } \\
\text { Student } \\
\text { Affairs Unit }\end{array}$ & BS in IT/CELTA & IT specialist & Yes & 0 & 9 \\
\hline Natlus & Pakistani & $\begin{array}{l}\text { Head of } \\
\text { Academic } \\
\text { Coordination } \\
\text { Unit }\end{array}$ & $\begin{array}{l}\text { MA in Applied } \\
\text { Linguistics }\end{array}$ & $\begin{array}{l}\text { Teaching \& } \\
\text { Research }\end{array}$ & Yes & 0 & 5 \\
\hline Omar & Pakistani & $\begin{array}{l}\text { Head of } \\
\text { Quality } \\
\text { Assurance } \\
\text { Unit }\end{array}$ & $\begin{array}{l}\text { MA in English } \\
\text { Literature }\end{array}$ & $\begin{array}{l}\text { University } \\
\text { Teaching }\end{array}$ & No & 3 & 9 \\
\hline Peter & American & $\begin{array}{l}\text { Head of } \\
\text { Professional } \\
\text { Development } \\
\text { Unit }\end{array}$ & MA TESL & $\begin{array}{l}\text { University } \\
\text { Teaching }\end{array}$ & Yes & 0 & 5 \\
\hline Rahat & British & $\begin{array}{l}\text { Head of } \\
\text { External } \\
\text { Student } \\
\text { Affairs Unit }\end{array}$ & PGCE/CELTA & $\begin{array}{l}\text { Secondary } \\
\text { School } \\
\text { Teaching }\end{array}$ & Yes & 0 & 3 \\
\hline
\end{tabular}




\begin{tabular}{|l|l|l|l|l|l|l|l|}
\hline Sachin & Canadian & $\begin{array}{l}\text { Head of } \\
\text { Curriculum } \\
\text { Unit }\end{array}$ & $\begin{array}{l}\text { MBA/TEFL } \\
\text { Certificate/CELTA }\end{array}$ & $\begin{array}{l}\text { Hotel } \\
\text { Management }\end{array}$ & Yes & & \\
& & & 6 & 4 \\
\hline
\end{tabular}

\subsection{Data collection and analysis}

I considered qualitative methods to be the most appropriate data collection tools for this case study. According to Denzin and Lincoln (2003), qualitative approaches help researchers to capture the verbal descriptions, analyses and interpretations of the participants' views. A case study design within the qualitative research framework enabled me to explore the complex social phenomenon of teacher leadership in the real-life context of the ELI, where boundaries between the context and the phenomenon are not clearly defined (Yin, 2011). Keeping this in mind, I opted for semi-structured interviews as a primary tool for gathering qualitative data which was complemented by an open-ended questionnaire. The open-ended questionnaire was mainly used to further explore unsaturated categories and give more depth to the data. However, the researcher could not use other tools such as document analysis, archival records, direct observation or physical artefacts, mainly due to the practical constraints of the traditional top-down bureaucratic system. The interview questions were generated in the light of my personal observations of leadership practices at the ELI and the key areas identified in the literature on teacher leader development.

The transcripts of 12 interviews and 8 open-ended questionnaires were analysed using Nvivo 10. For analysis, the researcher adopted an eclectic approach by combining the guidelines given by Creswell (2012) and Saldaña (2009). The process of data analysis was completed in steps as follows:

First, I did an initial reading of the transcripts to obtain a general sense of the data as suggested by Creswell (2012). This prepared me for the coding process of the data. Overall, the initial reading reflected the professional and academic backgrounds of the teacher leaders, leadership knowledge and the leadership roles they had performed over the years.

The second step involved a more thorough reading to code the transcripts, following the recommendations by Creswell (2012) and Saldaña (2009). In the first cycle of coding, the data was openly coded with no preconceived notions and there were 181 initial open codes. Most of the codes were descriptive in type. I did not follow Creswell's (2012) guideline to divide text into segments of information as the data was in NVivo 10; rather, I identified common patterns and assigned initial codes using NVivo nodes. Other repetitive patterns, passages, excerpts and consistencies were dragged into the same code which helped in organising the data "not just because they were exactly alike or very much alike, but because they might also have something in common - even if, paradoxically, that commonality consists of differences" (Saldaña, 2009, p. 6). For example, codes that described the 'top-down management' had both positive and negative opinions of the interviewees, however, they had a similar subject. Consequently, the codes were refined and reduced to 119 open codes.

After the two cycles of open coding, in the second phase of data analysis, 119 codes were subsumed under 18 broad categories which encompassed codes with identical concepts. For the purpose of this study, only four categories were chosen: the impact of bureaucracy, hierarchical structures at ELI, teacher leader roles and understanding teacher leadership. The entire coding process was iterative as I went back to the codes, refined them, renamed and reworded them to make them more representative of the interviewees' talk. As suggested by Saldaña (2009), the four categories were checked in the light of the research question. The grouping of categories under the research question made it easy to reflect on them and develop four 
overarching themes. This article includes one major theme 'the nature of teacher leadership' whereas other themes have been published elsewhere.

\section{Findings}

The findings illustrate the perceptions of EFL teachers about teacher leadership and their leadership roles at the ELI. The theme 'The nature of teacher leadership' explains the notion of teacher leadership and teacher leadership roles from the perspectives of EFL teacher-leaders at the ELI.

\subsection{The nature of teacher leadership}

As the key aim of this study was to explore the concept of 'teacher leadership' at the ELI, it appears to be a novel idea, as more than half of the participants seem unaware of its definition and function. Ismael, with an MA in educational leadership, has no knowledge of the construct of teacher leadership and, although Harrison, Ibrahim and Khan, with post-graduate leadership qualifications, are aware of the term, they have never used it at the ELI. Likewise, Omar has identified it; however, he finds it inappropriate for bureaucratic organisations like the ELI. He said, 'I heard about teacher leadership, but my objection is that you can't have teacher leaders in this technocratic context, it's a kind of misnomer'. (Omar)

In the light of his leadership background and experience, Khan perceives the construct of teacher leadership as a term that serves different purposes in educational settings depending on the leadership role and its requirements.

Teacher leader is a very broad term. In different contexts, it means different things, but generally teacher leader means one of the senior teachers who participates in all kind of managerial roles. He's the middle manager who's responsible for the curriculum delivery, testing and the supervision of instruction. (Khan)

As the remaining eight participants had no knowledge of the term 'teacher leader' or 'teacher leadership', they were asked to read the definition by Katzenmeyer and Moller (2009) and give their opinions. Sachin, Hamza and Rahat note that the definition by Katzenmeyer and Moller (2009) have similar features to the teacher leadership roles they performed at the ELI.

This definition is closer to our context as teacher leaders lead beyond the classroom and contribute to the community of EFL learners and teachers. (Hamza)

Interestingly, Moh, Natlus and Gray find the definition by Katzenmeyer and Moller (2009) more or less similar to the responsibilities teacher leaders had at the ELI. However, Natlus points out that some of their roles bear more signs of 'a manager than a teacher leader' due to their operational responsibilities. Nevertheless, as the roles fit very well with the definition, Rahat prefers the term teacher leader over academic coordinator.

I think teacher leader also has got a similar sort of role because he leads and is the leader of the teachers. What I understand from the coordination and that's the general understanding of the term is to be a facilitator and help teachers in the classroom and beyond. So, it's very much what we're doing here but a different term (teacher leader) is used, which is softer than the terms supervisor, manager and coordinator. It does sound a bit more politically correct. (Rahat) 
Ibrahim considers teacher leadership the manifestation of one's strong academic background, varied professional experience and role-related skills. He does not perceive teacher leadership as an extension of bureaucratic structures; rather it is the individuals' knowledge and skills that earn them this position. He states:

Any teacher within a group could be a leader because he enjoys that position as a leader due to his knowledge, expertise, his intellectual level, his teaching abilities and research skills. So, this is his personal ability as a professional in the field that influences his colleagues, his seniors or his students. I believe that teacher leader positions don't come from the hierarchy or legal authority. It's not the administrative leadership. It's based on your knowledge as a teacher, your ability as a teacher, and the respect that you enjoy as a teacher in your workplace. (Ibrahim)

When a question was asked about the specific roles teacher leaders performed in various units, the participants mentioned eleven instructional and eleven operational roles at the ELI (Table 3). Gray, Hamza, Harrison, Ibrahim, Khan, Peter and Sachin consider their roles instructional in nature based on their expertise in a particular area, whereas five other participants deem their roles operational and managerial in nature. These roles have been categorised in the light of the three teacher leadership waves by Silva et al. (2000); however, these operational and instructional aspects fit well with the first and second waves of teacher leadership as summarised in table 3.

Table 3: Roles and responsibilities of teacher leaders at the ELI

\begin{tabular}{ll}
\hline Operational/Managerial roles & Instructional roles \\
\hline Monitoring teachers' attendance & Professional development specialist \\
\hline Facilitating teachers' classroom issues & Curriculum development specialist \\
\hline Monitoring teachers' office hours & Mentoring teachers \\
\hline Conducting annual evaluation for teachers & Teacher supervision \\
\hline Preparing teaching schedules & Giving feedback to teachers \\
\hline Managing exam materials \& venues & Coaching junior team members \\
\hline Working on quality assurance tasks & Giving PD workshops \\
\hline Handling E-learning services & Material development specialist \\
\hline Conducting accreditation process & Developing tests/exams \\
\hline Counselling students & Supervising joint research projects \\
\hline
\end{tabular}


The responses suggest that EFL teacher leaders have a wide range of operational roles and responsibilities, such as monitoring teachers' office hours, preparing teaching schedules and managing examination materials. On the other hand, EFL teacher leaders with instructional roles are responsible for jobs such as curriculum development, teacher supervision and mentoring of teachers. However, their jobs somehow bear managerial features too, as Peter explains:

The way I envision my role in the PDU is that of a professional development specialist, therefore, I should do things to help and encourage teachers to develop. However, there are administrative responsibilities that make it a significant aspect of my job. (Peter)

The data also suggest that five participants in operational positions go beyond their prescribed roles to influence others and achieve assigned tasks. For example, Natlus had two key roles - as facilitator and evaluator - but he mentions various other responsibilities as well:

$$
\begin{aligned}
& \text { My scripted role as a head of academic coordination unit is to give coordinators feedback on their tasks, offer them } \\
& \text { coaching, conduct end of the year evaluation of the instructors, communicate and explain the ELI and university's } \\
& \text { policies to the instructors, set common guidelines for the coordinators and monitor their performances as well as } \\
& \text { facilitate the administration in the implementation of ELI policies. (Natlus) }
\end{aligned}
$$

Khan believes that teacher leadership at the ELI is a combination of top-down and bottom-up approaches in which teacher leaders aim to facilitate fellow teachers and top management by adopting more flexible approaches:

We're all middle managers and we realise that when we're dealing with teachers, a lot of bottom-up information is important which we convey to administration. We try to minimise the top-down approach. On the other hand, when we deal with higher administration, it's totally top-down. (Khan)

The above excerpt gives an important insight into the nature of leadership structures and practices at the ELI, which are further elaborated in the participants' views of the leadership model at the top. The participants identify a top-down management model at the ELI that is run by a group of individuals who command authority and control the system. 10 out of 12 Interviewees call it a "typical top-down", "hierarchical" and "bureaucratic system", that is deep-rooted in Saudi higher education institutions. The comments from Natlus and Moh exemplify this view:

It's a typical hierarchical and top-down management model. (Natlus)

The structure of the institution that I work at is highly bureaucratic and centralised. On top of that, the decisions that are to be made within our unit both on an academic and administrative level can come from various higher ups. (Moh)

While ten participants consider it inflexible, two of them do not find it a completely top-down management model. For example, Ibrahim states:

It's not an absolutely top-down working environment as I feel a lot of concentration takes place that makes it more participatory and collaborative. I can see there's a culture of frequent professional meetings here as compared to Canada where I didn't experience many meetings. (Ibrahim)

Ibrahim's description of the management structure contains elements of frequent collegial interactions and sharing of views between the teacher leaders and top management. Khan shares a similar opinion: 
The only thing is that the higher administration is flexible. They listen to your suggestions if they make sense to them. However, somebody with TESOL background has to educate them about the sensitivity of the job. (Khan)

Khan's opinion shows that, although the top leaders are prepared to compromise, they might fail to understand the complexities of a language institute due to their lack of TESOL background. Table 4 summarises role-related challenges that teacher leaders face at the ELI.

Table 4: Role-related difficulties

\begin{tabular}{lll}
\hline \multicolumn{1}{c}{ Difficulty } & Sources & References \\
\hline Lack of professional support & 10 & 15 \\
\hline Control and accountability & 9 & 13 \\
\hline Bureaucracy & 9 & 12 \\
\hline Lack of autonomy & 8 & 12 \\
\hline Lack of appreciation & 10 & 10 \\
\hline Teacher resentment & 9 & 10 \\
\hline The absence of collaboration among the units & 6 & 6 \\
\hline Administrative workload & 6 & 6 \\
\hline Box-ticking and paperwork & 5 & 6 \\
\hline Earning teachers' trust & 5 & 5 \\
\hline
\end{tabular}

Unlike Ibrahim and Khan, the remaining ten participants associate various issues (Table 4) with the hierarchical leadership system that make their roles difficult at the ELI. They believe that, due to the top-down policies, the workplace context does not encourage collaborative practices, as it prevents the unit heads from collaborating on professional matters. Gray summarises it nicely:

There's a complete disconnect between the various units, purely due to the technocratic system. The heads of the various units should discuss and improve the system on their own. For example, the research people don't talk to the curriculum, no collaboration between the two. There's a sense of 'why put in so much hard work' when there's nothing from the leadership and there's no support from the management. (Gray)

Moreover, the data reveal the lack of support and appreciation for the teacher leaders that causes stress, anxiety and frustration. Ten participants voice such concerns. 
The top management is the source of stress and they don't realise how stressful this job is. There's no support, whenever they see you in person they might appreciate you, but in policy they don't support you at all. (Rahat)

The data also illustrate the fact that due to sheer bureaucracy, teacher leaders lack autonomy which restricts their roles to operational duties. Sachin's view is representative of what seven other participants express.

We don't have power to make decisions as they're made by individuals at the top. We only follow their verdicts and implement the top-down polices. (Sachin)

The stressful and demanding roles often affect the retention rate of the teacher leaders. While pointing out the element of stress, Khan mentions that teacher leaders usually fail to cope with pressure and leave their positions fairly soon.

A number of people who capitalised on these opportunities quit due to stress. So, there's a barrier, stress and confusion, once you pass that then you remain steadfast, you start learning, but some people quit before that time comes. (Khan)

Notwithstanding the challenging professional environment for the teacher leaders owing to their lack of decision-making powers, as they describe above half of them somehow manage to derive power from their positions in the hierarchy and exercise their authority to achieve organisational objectives. The comments from Ismael and Peter show how their hierarchical positions enable them to influence fellow teachers and implement institutional policies.

I can influence people and provide directions to my group because of my administrative role in the organisation. It's a kind of vertical position that I have colleagues who are working with me in this unit, are bound to follow my directions because of my position in the hierarchy. (Ismael) In this culture, the position itself adds weight which helps you with your role. (Peter)

The hierarchical leadership positions might have enabled teacher leaders to influence teachers and implement institutional policies; however, nine of them believe that such authority does not help them with gaining teachers' trust and bridging the gap between teachers and higher management at the ELI. Khan stated:

In such positions, the biggest challenge is that when you speak on behalf of the administration, teachers see you as an enemy, as an alien and compliance becomes an issue. If you cannot make them comply, then in the eyes of the top management you are incompetent. So, it's a difficult position really. For me TESOL practice or methodology wasn't a problem, winning teachers' confidence was a challenge. (Khan)

This lack of trust often affects teacher leaders' relationship with fellow teachers. As Table 4 shows, nine participants experience resentment from the teachers. The extracts from Omar and Sachin's interviews denote this point:

It's very challenging. At times in the meetings heated debates and arguments will go on. Literally teachers would stand up and shout. (Omar)

There's a lot of resentment and resistance from teachers which isn't good for a healthy professional environment. (Sachin)

Expanding further on this notion, Natlus explains that teachers often perceive coordinators and observers as a threat to their jobs, a phenomenon that makes teacher leadership roles difficult. 
Teachers think that the coordinators' roles at the ELI is just like policing or spying on instructors, as their objective used to be finding out the weaknesses of the instructors and firing them. This is the general perception that affects our jobs. (Natlus)

Despite teacher resentment, four participants strive to establish collegial relationship with teachers at the ELI. They consider it important for motivating, influencing and mobilising teachers in a bureaucratic workplace to realise organisational goals. Like Natlus, Khan and Hamza, Harrison too indicates that a collegial approach helps him to get things done.

I like to motivate my fellow teachers and colleagues by asking them to remember the true success and joy of teaching students and help them see what a good future looks like. Additionally, I like to share ideas and strategies. This way, everyone feels empowered and they can share positive ideas, which eventually look good, not only on me as a leader, but on everyone as a whole team. (Harrison)

Since they lack autonomy, they have to find other ways of influencing teachers that would possibly reduce the impact of top-down management. Natlus further elaborates this process in detail:

You must have a special meeting with the instructors whenever you implement a new policy by the ELI as a manager. Although it's not a written policy but before its implementation you must take teachers into confidence. One should explain the nature, objectives and goals of the policy and give a rationale why such a step should be taken. This will help to avoid negative feelings of the general staff towards the administration and we can focus more on our tasks. (Natlus)

The above extracts show that teacher leaders try to create a pressure-free environment for the teachers to meet the expectations of the top management.

Despite the difficulties summarised in Table 4, eight participants notice a positive influence of the hierarchical leadership structure on their leadership roles. For example, this system helps Ibrahim to organise his professional work in a better way and assign tasks to teachers and group members in a systematic manner.

Basically, this top-down management system disciplines you more, this is what l've learnt from this system. It helps you when you're required to meet certain pre-determined objectives and delegate work. (Ibrahim)

Similarly, Peter supports this view and said, "Hierarchical leadership model helps me in that I know exactly who I have to contact for any academic issue" (Peter). It also facilitates Hamza to have "clear roles and responsibilities and have a clear chain of command" (Hamza). Likewise, for Ismael the top-down management model proves crucial in meeting organisational objectives as it offers them a structure and plan.

The vertical structure of leadership helps organise and discipline the entire work at all positions. In view of completing my tasks and reporting to my supervisors and then to control and get things done on time, l've to seek report from my colleagues working under my supervision. I find this hierarchical management productive, efficient and results oriented. (Ismael)

However, four interviewees express their displeasure at the top-down management system. For instance, Omar calls it a "flop show". For Sachin "it's a double face thing, hypocrisy... an artificial setup". These aspects of the management model at the ELI make the teacher leaders' job more of a robotic nature as explained by Harrison: 
If you make anything bureaucratic as it is, broad levels of control and accountability, then the coordinators have a very clear job, they just proceduralise and do it. That responsibility just shows that they do what they are told to do. They don't look at the sense of right and wrong. They might - but if they considered it wrong why would they do it? (Harrison)

The above extracts also reflect the impact of a technocratic system that contains the element of control and accountability. Moh points out how that distances the management from the daily workings of the Institute: "This is not a favorable situation as the higher-ups don't really have a pulse on what's happening in the unit on a day to day basis" (Moh). Similarly, five participants indicate excessive administrative tasks, unnecessary box-ticking and workload that emanate from their operational duties and make their roles difficult:
In Saudi Arabia. If you're in a leadership position, you must meet deadlines and you have to come up with ideas on the fly otherwise you'll be stuck. You've to keep records of everything on daily basis. (Harrison)
It's quite hectic. There's so much to do and there's so much paperwork and documentation all done by the coordinators. (Rahat)

The above extracts show that the hierarchical leadership model is a source of stress and bureaucracy; however, at the same time it helps teacher leaders with strategic planning at the ELI.

\section{Discussion}

\subsection{The range of teacher leadership roles at the ELI}

Teacher leadership, a commonly used concept in international literature, appeared to be a new idea in this study, which is a contribution to the field of teacher leadership in TESOL. Although the concept is new in the EFL context, the roles EFL teacher leaders identified in Table 3 have similarities, characterising the second wave of teacher leadership (Silva et al., 2000) as they are based on the individuals' professional and pedagogical expertise. The three waves of teacher leadership by Silva et al. (2000) is a useful lens to see how teacher leadership appears in the EFL context of this study. Moreover, the roles suggest that the three waves are not time or context-bound; rather they are still relevant in EFL settings with more hierarchical structures, i.e. Saudi EFL context.

The teacher leadership roles at the ELI are formal in nature, involving teacher-leaders going beyond classroom instructions and contributing to the Institute on a wider scale, that is, developing a curriculum, preparing tests and teaching materials, and supervising teachers. Similarly, teacher-leaders perform operational duties such as head of the ACU, head of the student affairs and head of the quality assurance units, in which they are mainly responsible for policy implementation. These roles are similar to the first wave of teacher leadership (Silva et al., 2000) which focuses on the administrative and managerial aspects of teacher leadership. Identical to the second wave of teacher leadership roles, such as middle managers, mentors, curriculum developers and staff developers, have been reported by the EFL teacher leaders, which are also found in US school contexts (York-Barr $\&$ Duke, 2004; Thompson \& Wolstencroft, 2015). However, the participants have specific organisational roles, too, as head of the research unit, head of the E-learning unit and head of the student affairs unit, which are not found in the international literature on teacher leadership roles. In addition, all these roles are formal and there is no concept of informal leadership roles at the ELI, 
which makes this context different from the US and the UK schools where teachers often have informal leadership roles (Katzenmeyer \& Moller, 2009)

The list of teacher leadership roles (Table 3) at the ELI shows that EFL teacher leaders perform a variety of instructional and operational roles. This diversity of roles is also evident in their day-to-day activities. For example, the head of the PDU or Elearning unit has instructional leadership responsibilities, whereas the head of the ACU performs a more operational role. This diversity in their roles can be linked to the difference in objectives and functions of the units that co-exist and play a different but vital role in the integration of the ELI. In a nutshell, the presence of the three waves and the ways how they facilitate the operation of the ELI show the intricate nature of EFL institutes based in hierarchical leadership structures. Nevertheless, their presence at the Institute makes it a unique case.

The teacher leaders' perceptions of their roles determine the nature of teacher leadership in this Saudi EFL context and are similar to the existing literature on this topic. As defined by Katzenmeyer and Moller (2009), the participants teach EFL classes and simultaneously perform their leadership roles in the hierarchy of the institute to achieve organisational objectives. The definition by York-Barr and Duke (2004) also shows similar characteristics but, according to them, the whole exercise is to enhance student outcomes, whereas the current study does not indicate whether the teacher leaders' aim is to improve learner performance. Thus, more research in this direction may help to demonstrate the impact of teacher leadership practices on EFL learning and teaching practices.

\subsection{A hierarchical leadership model at the ELI}

The perceptions of leadership practices at the top and middle levels enable us to see how teacher leadership works at the ELI. The findings show that a typical top-down management model is in place that shapes the leadership practices at the ELI. The organisational structure of the Institute is highly bureaucratic and centralised with top-down policies that often hinder the functioning of teacher leadership.

Lack of autonomy, teacher resentment and lack of support for teacher-leaders are overarching characteristics of the hierarchical organisation of the ELI that apparently reduce the effectiveness of EFL teacher leadership. Since teacher leaders lack decision-making powers and professional support from the top management, they cannot go beyond their scripted responsibilities; rather, they must follow a certain set of procedures. Owing to the negative influence of the top-down management system, it can be said that a more flexible leadership model at the top may expand its benefits to EFL teachers and students. Facilitating teachers and teacher leaders to become autonomous practitioners would benefit the institution and individuals to cope with external and internal challenges and focus on organisational effectiveness.

As accountability and task achievement become the key goals of a centralised system, individuals in leading positions exercise their authority to influence their subordinates and achieve organisational objectives. In the context of this study, accountability measures lead to teachers' anxiety and their apprehension regarding possible repercussions in case of failure to meet the expectations of their superiors. As a result, the teacher leaders find it hard to bridge the gap between the top management and fellow teachers. These findings are in line with Sanocki (2013), and Tschannen-Moran (2009), who established the negative influence of bureaucratic structures on teacher leadership roles. Furthermore, the culture of mistrust and bureaucracy hinders collaboration among the units at the ELI, as heads of the units are not answerable to each other, but report to the vice deans.

The findings have revealed various administrative challenges that participants associate with teacher leadership roles at the ELI, as presented in Table 4. Administrative workload seems to be a common issue for the teacher leaders, where most of their 
time is consumed by paperwork, maintaining records and ensuring policy implementation. The range of administrative tasks at the ELI is indicative of increased accountability in Higher Education as excessive administrative responsibilities focus on standardisation, and leave little scope for exercising leadership within the roles (Tschannen-Moran, 2009).

Apparently, there is insufficient evidence in the literature that supports the positive influence of hierarchical leadership practices on teacher leadership roles. Nevertheless, it is indeed a rare feature of the ELI that, despite the lack of autonomy and support, teacher leaders manage to operate effectively in a technocratic system. On a positive note, the existing power structure has guided the participants by offering them a clear structure, a plan and a strategy that facilitates their leadership roles. Moreover, it has channeled their roles and given them a clear line of action and raised their awareness of cultural and professional complexities at the ELI. This positive influence may appear surprising, but it is possible to say that stern bureaucratic structures sometimes result in guiding employees and achieving organisational objectives. Nevertheless, the professional obligations of the teacher leaders might have influenced their beliefs and prompted them to remain cautious and conscious of any possible consequences of criticizing the top management.

\subsection{Shared leadership practices at the ELI}

Despite the top-down leadership model, the qualitative findings reveal the existence of distributed or shared leadership approach among EFL teacher leaders in their respective groups, which is the feature of the third wave of teacher leadership.

Although their positions in the hierarchy offer them power to influence others, teacher- leaders prefer collegial relationship with group members and subordinates to achieve organisational objectives. This collaborative approach by teacher-leaders also reflects their professional cognisance of the shared responsibilities that have facilitated their performance. As bureaucratic structures affect collaboration between the unit heads, teacher-leaders aim to build trusting relationship with colleagues in their groups to maintain an amicable working environment.

In the context of this research, professionally sound teacher-leaders have exhibited their ability to neutralise the negative influence of hierarchical leadership on their practices by adopting shared leadership models within their groups. Reliance on one another indicates that, irrespective of social, political, educational and professional backgrounds, a group of individuals can have a shared purpose while working on a project. For instance, the team of academic coordinators have identical job descriptions, hence their mutual collaboration helps them complete projects in a swift manner. Since all the participants are non-Saudis and 11 out of 12 are non-Arabs educated in more democratic institutions around the world, an interpretation of this is that they possess a refined sense of professionalism and work ethics, which lead to their distributed leadership practices within the units. Another interpretation of this phenomenon is that the pressure of accountability in the hierarchical leadership setup at the ELI coerces them to be more interdependent in their respective groups and leave no space for any professional setback.

\section{Implications for teacher-leaders in TESOL}

Since the 1980s, the concept of teacher leadership has commonly been used in western school contexts; however, it is not a frequently used term the field of TESOL. In the immediate context of this research, which is an EFL institute, this study has introduced the concept of teacher leadership to enhance awareness among teachers, teacher-leaders in middle-level leadership positions, top leadership and policy makers about the significance of teacher leadership. Indeed, it contributes towards an understanding of how teacher leadership has served as a change agent in western contexts in which individuals in such positions influence change, work in collaboration with colleagues and contribute to organisational outcomes. However, research has not 
found these features of teacher leadership in other EFL/ESL contexts. Thus, this study has provided EFL teacher-leaders with a foundation to see their leadership roles from a different perspective and align their practices with international standards. The teacher leadership roles found in this study are a new addition to the body of literature in mainstream education as well as in TESOL. In addition, current and prospective TESOL professionals in teacher leadership roles can raise their awareness of the nature of teacher leadership and its role-related challenges in EFL contexts, which can contribute to their leadership capacity.

\section{Conclusion}

The concept of teacher leadership has not been used by the teacher-leaders in the context of this study, but various features of teacher leadership are conspicuous in teacher leadership roles at the ELI. For example, EFL teachers teach and lead simultaneously, influence their colleagues to achieve organisational objectives and help each other to learn and improve their leadership skills (Katzenmeyer \& Moller, 2001; York-Barr \& Duke, 2004). In addition, the three waves of teacher leadership described by Silva et al. (2000) help us see the different facets of teacher leadership at the ELI. Interestingly, all three waves are evident in the teacher leaders' roles in the ELI. The top-down management policies limit teacher-leaders' roles to the first wave of teacher leadership with inadequate power and more managerial and operational responsibilities, and policy implementation. The wide range of roles, based on teacher leaders' professional expertise and pedagogical skills, reflects the second wave of teacher leadership at the ELI. Finally, collaborative efforts and teamwork among the group members to achieve organisational objectives are the features of the third wave of teacher leadership. The combination of three teacher leadership waves plays a key role in organisational cohesiveness which makes this context a unique case in the field of TESOL.

Although a top-down management system has its negative influences on educational institutions, it can be considered an effective way of management in large institutes such as the ELI where more than $250 \mathrm{EFL}$ teachers work and follow a chain of command that helps different stakeholders to know and execute their assigned roles in a linear way. In addition, participatory leadership practices in the middle-level are feasible in a typical top-down management model which can aid teacher leaders to minimise the negative influence of the top-down polices on their own practices. As a hierarchical leadership model dominates at the top, it can contribute to EFL teacher leaders' effectiveness in their leadership roles and, to an extent, assist them with successful dispensation of their leadership roles. The roles performed in more flexible organisational structures may offer teacher-leaders more autonomy, but the individuals' collaborative efforts in less autonomous workplaces can neutralise the impact of bureaucratic power structures.

\section{Acknowledgement}

The findings presented in the article are part of the doctoral thesis submitted to the University of Exeter, UK in October 2016.

\section{References}

Al-Eisa, E.S., \& Smith, L. (2013). Governance in Saudi higher education. In L. Smith \& A. $\quad$ Abouammoh $\quad$ (Eds.), Higher Education in Saudi Arabia: Achievements, Challenges and Opportunities (Vol. 40, pp. 27-35). New York \& London: Springer Dordrecht Heidelberg.

Bangs, J., \& MacBeath, J. (2012). Collective leadership: the role of teacher unions in encouraging teachers to take the lead in their own learning and in teacher policy. Professional Development in Education, 38, 331-343. 
Causton-Theoharis, J. \& Theoharis, G. (2008). Creating inclusive schools for all students. The School Administrator, 65(8), 24-31.

Cohen, L., Manion, L., \& Morrison, K. (2011). Research Methods in Education. Milton Park. Abingdon, Oxon, England: Routledge.

Creswell, J. W. (2012). Qualitative Inquiry and Research Design: Choosing among Five Approaches. London: Sage.

Denzin, N., \& Lincoln, Y. (2003). Handbook of Qualitative Research $\left(2^{\text {nd }}\right.$ ed.). London: Sage.

El-Sanabary, N. (1994). Female education in Saudi Arabia and the reproduction of gender division. Gender and Education, 6, 141150.

Ezzi, S.W., Teal, E.J., \& Izzo, G.M. (2014). The influence of Islamic values on connected generation students in Saudi Arabia. Journal of International Business and Cultural Studies Volume, 9, 1-19.

Frost, D. (2010). Teacher leadership and educational innovation. Zbornik Instituta za pedagoska istrazivanja, 42, 201-216.

General Secretariat, C. o. H. E. 2007. Regulations of the Saudi Council of higher education and universities. Riyadh KSA: Imam Mohammad bin Saud Islamic University Press.

Harris, A. \& Muijs, D. (2004). Improving Schools through Teacher Leadership. Berkshire, UK: Open University Press

Katzenmeyer, M. \& Moller, G. (2009). Awakening the sleeping giant: Helping teachers develop as leaders (3 ed.). California: Thousand Oaks, Corwin Press.

Katzenmeyer, M. \& Moller, G. (2001). Awakening the Sleeping Giant: Helping Teachers Develop as Leaders: Thousand Oaks, Corwin Press.

Liu, J. (2008). Preface to. Leadership in English language teaching and learning. In C. Coombe,

M.L. McClaskey, L. Stephenson, \& N. Anderson, J. (Eds.), Leadership in English Language Teaching and Learning. USA. The University of Michigan Press.

Margolis, J., \& Doring, A. (2012). The fundamental dilemma of teacher leader-facilitated professional development. Do as I (kind of) say, not as I (sort of) do. EducationalAdministration Quarterly, 48, 859-882.

Muijs, D., Chapman, C., \& Armstrong, P. (2013). Can early careers teachers be teacher leaders? A study of second-year trainees in the teach first alternative certification programme.

Educational Management Administration \& Leadership, 41, 767-781.

Murphy, J. (2007). Teacher leadership: Barriers and supports. In T. ownsend (Ed.), International Handbook of School Effectiveness and Improvement: Review, Reflection and Reframing: The Netherlands: Springer Science \& Business Media.

Saldaña, J. (2009). The Coding Manual for Qualitative Researchers. London: Sage.

Sams, D. A. (2010). An Analysis of Leadership Beliefs and Practices of 25 TESOL Leaders. $\mathrm{PhD}$ thesis).Indiana, PA, US: Indiana University of Pennsylvania.

Sanocki, S. J. (2013). The Process of How Teachers Become Teacher Leaders and How Teacher Leadership Becomes Distributed within a School: A Grounded Theory Research Study. PhD thesis. Kalamazoo, MI, USA: Western Michigan University. 
Shah, S.R. (2014). Empowering EFL teachers through distributed leadership: A critical

perspective on leadership practices in an educational institution. International Journal of Business and Social Science, 5(10), 9-25.

Silva, D., Gimbert, B., \& Nolan, J. (2000). Sliding the doors: Locking and unlocking possibilities for teacher leadership. The Teachers College Record, 102, 779-804.

Swanson, J., Elliott, K., \& Harmon, J. (2011). Teacher Leader Stories: The Power of Case

Thompson, C. \& Wolstencroft, P. (2015). Promises and lies: An exploration of curriculum of Further and Higher Education, 39, 399 416.

Tschannen-Moran, M. (2009). Fostering teacher professionalism in schools the role of Educational Administration Quarterly, 45, 217-247.

Wasley, P.A. (1991). Teachers Who Lead: The Rhetoric of Reform and the Realities of Press.

Yin, R. K. (2011). Applications of Case Study Research (3 ed.). London: Sage.

Yin, R. K. (1994). Case Study Research: Design and Methods. Beverly Hills, CA, USA: Sage.

York-Barr, J., \& Duke, K. (2004). What do we know about teacher leadership? Findings scholarship. Review of Educational Research, 74, 255-316.
Methods. USA: Corwin Press.

managers' experiences in FE. Journal leadership orientation and trust.

Practice. New York: Teachers College

from two decades of 